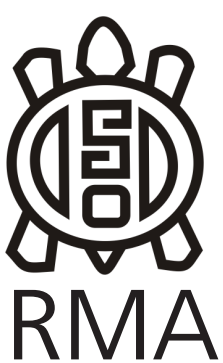

Arqueología

\title{
Resultados preliminares del sitio Zoko Andi 1. Aportes para la arqueología del curso inferior del río Colorado (Provincia de Buenos Aires)
}

\author{
Gustavo Martínez*, Gustavo Adolfo Martínez**, \\ Luciana Stoessel***, Ana Paula Alcaráz****, \\ Florencia Santos Valero*****, Gustavo Flensborg ${ }^{* * * * * *}$, \\ Pablo Bayala ${ }^{* * * * * *}$ y José Francisco Onorato ${ }^{* * * * * * * *}$
}

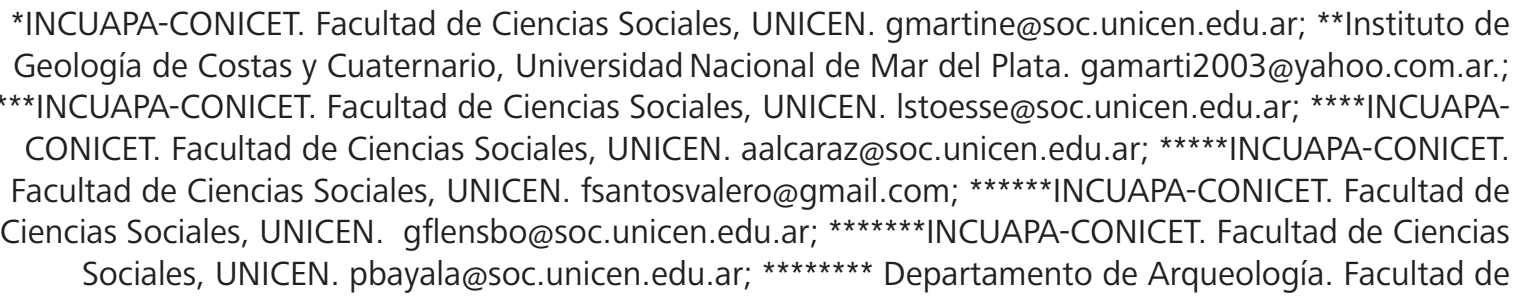
Ciencias Sociales, UNICEN. onoratojf@yahoo.com.ar;

\begin{abstract}
Resumen
El objetivo de este trabajo es presentar la cronología y las principales tendencias de los análisis geoarqueológicos, zooarqueológicos, de la tecnología lítica y de los entierros humanos recuperados en el sitio arqueológico Zoko Andi 1 (Pdo. de Patagones). Éste se localiza en una duna, sobre la margen derecha del curso inferior del río Colorado. Se obtuvieron nueve fechados radiocarbónicos provenientes de especímenes faunísticos, restos óseos humanos y carbón que ubican la cronología del sitio entre ca. 1500-400 años AP. Las dataciones obtenidas, en conjunción con los aspectos estratigráficos identificados, indican la existencia de al menos dos lapsos de ocupación. El primero de ellos se ubica en torno a los ca. 1500-1300 años AP (Holoceno tardío inicial), mientras que el otro se localiza en ca. 800-400 años AP (Holoceno tardío final). En este sentido, se trata del primer sitio del área en cuya secuencia se distinguen dos componentes que se corresponden con los dos bloques temporales del Holoceno tardío. Los resultados obtenidos hasta el momento en las distintas líneas de análisis se ajustan parcialmente a las tendencias propuestas en los modelos formulados para el área y son brevemente discutidas en este trabajo.
\end{abstract}

Palabras clave: transición pampeano-patagónica oriental; Holoceno tardío; geoarqueología; tecnología lítica; subsistencia; prácticas mortuorias.

Preliminary results of Zoko Andi 1 site. Contributions to the archaeology of the lower basin of the Colorado River (Buenos Aires province)

\begin{abstract}
The objective of this paper is to present the chronology and the main trends obtained from the results of geoarchaeology, zooarchaeology, lithics and human burials of Zoko Andi 1 archaeological site (Patagones district, Buenos Aires province). The site is located in a dune, on the right bank of the lower basin of the Colorado River. Nine radiocarbon dates from faunal remains, human bones and charcoal place the chronology of the site at ca. 1500-400 years BP. The chronology obtained in conjunction with stratigraphic aspects of the site indicates the existence of at least two components: the lower is located around ca. 1500-1300 years BP (Initial Late Holocene), while the upper is placed at ca. 800-400 years BP (Final Late Holocene). In this sense, Zoko Andi 1 is the first site of the area that exhibits two clearly distinguishable components, each one corresponding to the distinct temporal periods proposed for the Late Holocene. The results obtained for the analyzed lines of evidence are partially consistent with the trends of the models developed for the area, which are briefly discussed in this paper.
\end{abstract}

Keywords: eastern Pampa-Patagonia transition; Late Holocene; geoarchaeology; lithic technology; subsistence, mortuary practices.

Recibido 20-12-2013. Recibido con correcciones 07-06-2014. Aceptado 30-06-2014 
La arqueología del curso inferior del río Colorado posee un desarrollo reciente. La formulación inicial del modelo arqueológico y conductual propuesto para el Holoceno tardío en el área (Martínez 2008-2009) ha sido recientemente reevaluada y enriquecida a partir de la inclusión y profundización en el estudio de diversas líneas de evidencia (Alcaráz 2012; Armentano 2012; Flensborg 2012; Martínez y Martínez 2011; Martínez et al. 2012a; Santos Valero 2013; Stoessel 2012). De forma muy sintética, a partir de los resultados obtenidos de estas líneas, el modelo contempla cambios en las organizaciones conductuales y dinámicas poblacionales del Holoceno tardío. El Holoceno tardío inicial (ca. 30001000 años $C^{14}$ AP) se caracteriza por: a) la presencia de sitios de actividades múltiples y específicas, ocupados efímeramente; b) un énfasis en el empleo del componente residencial de la movilidad; c) una subsistencia basada en el consumo de guanaco y secundariamente venado, ñandú y vegetales; d) una amplia variabilidad tipológica de instrumentos líticos y de materias primas explotadas (tanto locales como extra-areales) a través de cadenas operativas simples; e) la presencia de modalidades de inhumación primaria. Por su parte, el Holoceno tardío final (ca. 1000-250 años $C^{14}$ AP) presenta las siguientes características: a) las ocupaciones fueron más estables y prolongadas, presentaron redundancia ocupacional y una mayor variabilidad intra e inter sitio; b) las estrategias de movilidad residencial y logística habrían sido empleadas conjuntamente; c) la subsistencia experimentó una diversificación en la base de recursos con la incorporación de especies de tamaño menor procedentes de diferentes ambientes (terrestres, marinos y fluviales) y se planteó un escenario de intensificación; d) la tecnología se caracterizó por una menor variabilidad tipológica de los instrumentos y de las materias primas empleadas con una optimización en el uso de los recursos líticos locales y areales, un incremento en la bifacialidad y cadenas operativas mas complejas; e) las prácticas mortuorias se complejizaron incluyendo una intensa manipulación de cadáveres, entierros secundarios y la existencia de áreas formales de entierro. Las características de los grupos cazadoresrecolectores del área de estudio para este periodo son parte de fenómenos socio-económicos y demográficos experimentados por las poblaciones pampeanopatagónicas que incluyeron un crecimiento poblacional, reducción de la movilidad, circunscripción espacial y nucleamientos demográficos, contactos inter-étnicos, redes sociales de interacción y complementariedad social en diferentes escalas (local, regional y extra regional) (Barrientos y Pérez 2004; Berón 2004; Favier Dubois et al. 2009; Gómez Otero 2006; Gordón 2011; Mazzanti 2006; Politis 2008; Prates 2008, entre otros). Investigaciones recientes en nuevos sitios del área, como el que aquí se presenta, aportan información novedosa para la comprensión de algunos aspectos como los arriba mencionados. En este sentido, el principal objetivo de este trabajo es realizar una caracterización inicial del sitio Zoko Andi 1 en lo que respecta a distintas líneas de evidencia. Por un lado, se presenta y discute la información referida a la geoarqueología y la cronología de las ocupaciones humanas, en relación con las principales dinámicas ambientales inferidas para el sitio. Por otro lado, se describen los primeros resultados y las tendencias principales obtenidas de los análisis zooarqueológicos, de la tecnología lítica y de los entierros humanos. En este sentido, los resultados preliminares alcanzados en este trabajo sólo permiten evaluar algunos aspectos del modelo descrito más arriba para la arqueología de la transición pampeano-patagónica oriental y para regiones aledañas.

El sitio Zoko Andi 1 (39 $28^{\circ} 10.3^{\prime \prime}$ LS y $63^{\circ} 5^{\prime} 58.1^{\prime \prime}$ LO) se encuentra ubicado en el curso inferior del río Colorado (partido de Patagones), sobre su margen derecha, a unos $80 \mathrm{~km}$ aguas arriba de su desembocadura (Figura 1A). El sitio fue visitado por primera vez en el año 2009 a partir de referencias brindadas por el Sr. J. L. Onorato. Se trata de un médano localizado a la vera del río donde años atrás, a partir de actividades relacionadas con la construcción de una defensa y el tendido de postes de electricidad, se puso al descubierto una importante cantidad de restos arqueológicos como huesos humanos, materiales de molienda, puntas de proyectil, cerámica, etc. En dicha oportunidad, se constató el potencial del sitio para luego comenzar con las tareas de prospección, sondeos y excavaciones sistemáticas, las cuales se desarrollaron entre Octubre de 2010 y Febrero de 2011. Hasta el momento se excavaron 10 cuadrículas (Figura 1B-C), totalizando una superficie de 11,74 $\mathrm{m}^{2}$.

\section{Marco geomorfológico, estratigráfico y cronológico}

Las características geomorfológicas del área de estudio corresponden a un relieve de superficies geomórficas relictuales disectadas tanto por el actual río Colorado como por paleovalles afuncionales. Las antiguas superficies geomórficas están formadas por relictos mesetiformes constituidos por las areniscas de la Fm. Río Negro, usualmente coronadas por una carpeta de "rodados patagónicos". Los paleovalles afuncionales están rellenos de sedimentos fluviales de la llanura aluvial madura, con facies de cauce areno-gravosas y de llanura de inundación, que incluyen depósitos de barras de meandros, lagos semilunares y albardones. Sobre este sustrato se apoyan dunas de escasa expresión morfológica (ver Martínez y Martínez 2011 y citas allí). El sitio Zoko Andi 1 se ubica sobre una de estas dunas, en la margen derecha del río Colorado, en el borde externo de un meandro (ladera de erosión). Se trata de una llanura aluvial madura donde el río tiene una alta dinámica y cuyas modificaciones en la traza del curso provocan erosión y depositación de sus antiguos depósitos y de otros sobreimpuestos, correspondientes a dunas semifijas.

Los estudios geoarqueológicos consistieron en el relevamiento de la estratigrafía de las secuencias analizadas. Se definieron unidades aloestratigráficas y edafoestratigráficas sobre la base de sus características 


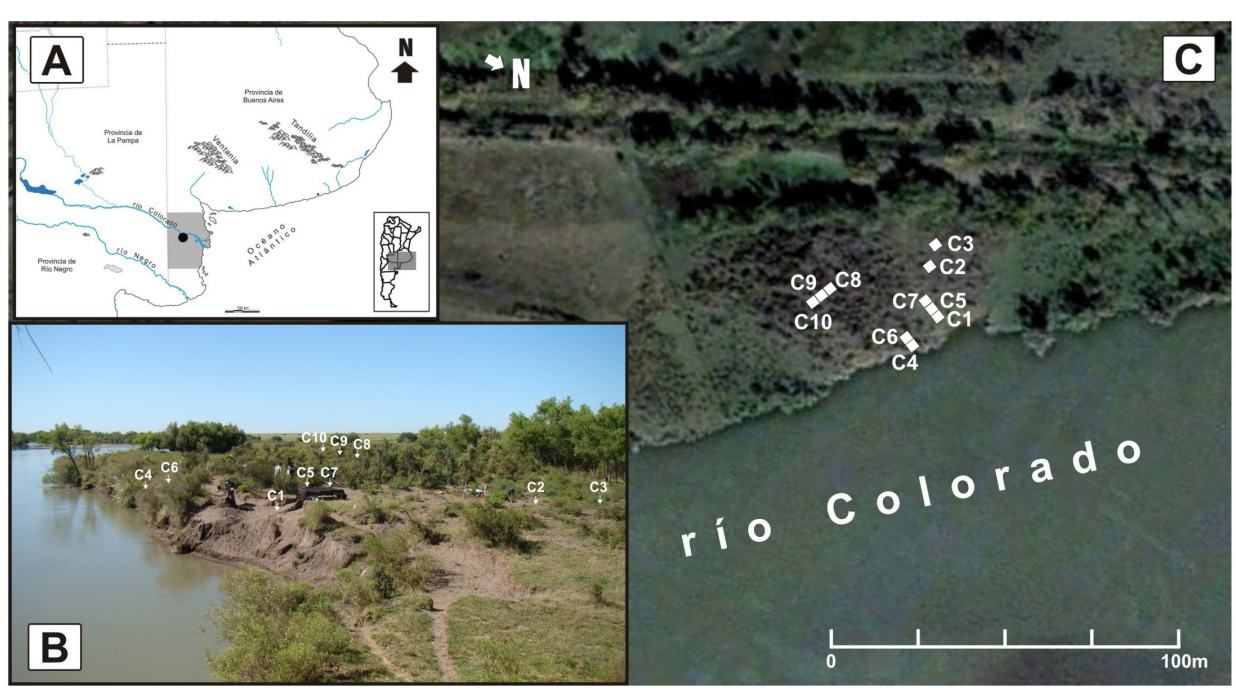

\begin{tabular}{|c|c|c|c|c|c|c|c|c|}
\hline $\begin{array}{l}\text { Unidad } \\
\text { Estrat. }\end{array}$ & $\begin{array}{l}\text { Horiz. } \\
\text { Pedog. }\end{array}$ & $\mathrm{pH}$ & $\begin{array}{l}\text { MO } \\
(\%)\end{array}$ & $\begin{array}{l}\text { C org. } \\
\text { (g kg-1) }\end{array}$ & $\begin{array}{c}\text { Arcilla } \\
(\%)\end{array}$ & $\begin{array}{c}\text { Limo } \\
(\%)\end{array}$ & $\begin{array}{c}\text { Arena } \\
(\%)\end{array}$ & $\begin{array}{c}\text { Clase } \\
\text { textural }\end{array}$ \\
\hline U1 & $A C$ & 9.55 & 0.56 & 3.30 & 3.07 & 5.03 & 91.90 & Arenosa \\
\hline \multirow[t]{2}{*}{ U2 } & $2 \mathrm{ACb}$ & 8.83 & 2.54 & 14.70 & 2.99 & 19.80 & 77.17 & $\begin{array}{c}\text { Arenosa } \\
\text { franca }\end{array}$ \\
\hline & $3 \mathrm{Cb} ?$ & 8.66 & 1.97 & 11.40 & 5.59 & 5.08 & 89.33 & Arenosa \\
\hline U3 & $3 C$ & 8.63 & 1.68 & 9.80 & 7.37 & 12.05 & 80.58 & $\begin{array}{c}\text { Arenosa } \\
\text { franca }\end{array}$ \\
\hline U4 & $4 C$ & 8.54 & 1.40 & 8.10 & 9.98 & 19.5 & 70.52 & $\begin{array}{l}\text { Franco } \\
\text { arenosa }\end{array}$ \\
\hline U5 & $5 \mathrm{Cb}$ & 8.68 & 0.14 & 0.80 & 13.96 & 51.93 & 32.11 & $\begin{array}{l}\text { Franco } \\
\text { limosa }\end{array}$ \\
\hline U6 & $6 \mathrm{Cb}$ & 8.69 & 0.56 & 3.30 & 18.58 & 33.98 & 47.44 & Franca \\
\hline
\end{tabular}

Tabla 1. Parámetros sedimentológicos y químicos de la secuencia de la Cuadrícula 6. Se destacan los valores de arcilla de las U5 y U6 que representan una sedimentación fluvial de baja energía. Los mayores valores de Carbono (C org.) y materia orgánica (MO) reflejan procesos pedogenéticos en la U2.

Table 1. Sedimentary and chemical parameters recorded through out the sequence of square 6 . Clay values of Units 5 and 6 indicate a low energy fluvial sedimentation. Higher values of carbon (C org.) and organic matter (MO) indicate pedogenetic processes in Unit 2. de textura, color, forma, tipo de límites, estructuras sedimentarias, grado de compactación y rasgos pedológicos (Figura 2). Asimismo, se llevaron a cabo análisis texturales y determinaciones químicas de $\mathrm{pH}$, materia y carbono orgánico (Tabla 1). Los relevamientos estratigráficos de detalle fueron realizados en las cuadrículas 4, 5, 6 y 7. En este trabajo se toma como perfil tipo el de la pared Oeste de la cuadrícula 6 (Figuras 1 y 2). Se definieron seis unidades aloestratigráficas (U6, U5, U4, U3, U2 (a y b), y U1), de las cuales se extrajeron las muestras para los análisis antes mencionados.

A partir de los resultados obtenidos, se estableció que las unidades 5 y 6 son de origen fluvial, en tanto las superiores son eólicas, destacándose que una de ellas (U2a) corresponde a un suelo enterrado (Figura 2). Los parámetros químicos y granulométricos que se observan en la Tabla 1 apoyan la génesis planteada anteriormente para las unidades aloestratográficas y los mayores valores de MO (materia orgánica) y CO (carbono orgánico) de las U2a y U2b reflejan los procesos pedogenéticos mencionados. La dinámica inferida a partir de estas líneas de análisis indica que hacia la base del perfil estratigráfico, la U6 se corresponde con una secuencia de meandro abandonado, en tanto la U5 muestra una discordancia que indica la culminación en la depositación de sedimentos fluviales y el inicio de los eólicos. Por encima, las unidades
4, 3 y 2 b indican procesos de sedimentación rápida que culminan con el suelo enterrado que corresponde a la U2a. Luego de estas condiciones de estabilidad y pedogénesis se observa otra discordancia, a partir de la cual se depositaron, bajo procesos de sedimentación rápida, los sedimentos de la U1 (Figura 2).

En la Tabla 2 y en la Figura 2 se presenta la información cronológica obtenida para el sitio y la ubicación estratigráfica de los materiales datados. De los nueve fechados, ocho fueron realizados por AMS, en tanto el restante es convencional. En el caso de los huesos de fauna datados, todos corresponden a desechos de fractura helicoidal de Lama guanicoe. Cuatro fechados radiocarbónicos, tres realizados sobre carbón y uno en hueso, recuperados de la cuadrícula 6, ubican a la U6 en el lapso de ca. 1500-1300 años radiocarbónicos AP. En la misma cuadrícula, una muestra de hueso proveniente de la U4 arrojó una edad de ca. 800 años AP. Otro hueso, obtenido de la U2b de la cuadrícula 1, fue datado en ca. 700 años AP. La datación de otro espécimen óseo recuperado en la U2a (suelo enterrado) de la cuadrícula 4, dio una edad de ca. 400 años AP. Finalmente, sobre la parte superior del médano (Figura 1), en las cuadrículas 8 y 9, dos entierros humanos fueron datados en ca. 1400 años AP (Tabla 2). Los estudios geoarqueológicos de estas cuadrículas localizadas sobre la parte superior del médano 

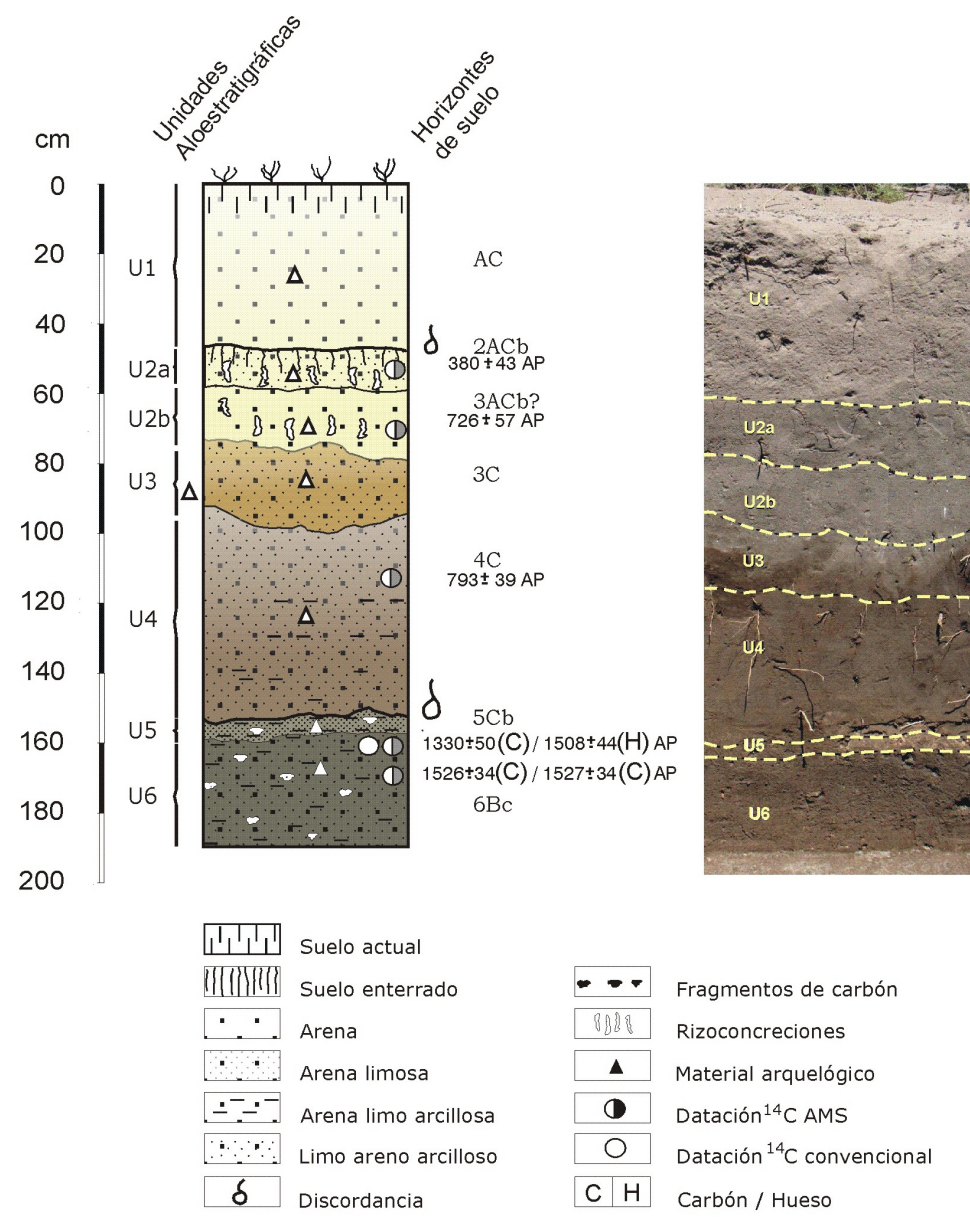

Fragmentos de carbón Rizoconcreciones

Material arquelógico Datación ${ }^{14} \mathrm{C}$ AMS Datación ${ }^{14} \mathrm{C}$ convencional

Carbón / Hueso
Sedimentación

rápida

\section{Discordancia}

Suelo Enterrado

(Estabilidad)

Sedimentación

rápida

Discordancia

Secuencia de Meandro abandonado

Figura 2: Secuencia estratigráfica. Izquierda: Unidades aloestratigráficas, suelos y cronología. Derecha: Dinámicas ambientales inferidas de las unidades y de sus parámetros químicos y sedimentarios.

Figure 2: Stratigraphic sequence. Left: Alostratigraphic units, soils and chronology. Right: Environmental dynamics inferred from the units and its chemical and sedimentary parameters.

\begin{tabular}{|c|c|c|c|c|c|c|}
\hline $\begin{array}{c}\text { Código } \\
\text { Lab. }\end{array}$ & $\begin{array}{l}\text { Espécimen } \\
\text { Cuadrícula }\end{array}$ & Material datado & Años $C^{14} A P$ & Años Cal AP & $\begin{array}{l}\delta C^{13} \\
(\square)\end{array}$ & $\begin{array}{c}\text { Unidad } \\
\text { Aloestratigráfica }\end{array}$ \\
\hline AA92657 & FCS.ZA1.C4.1 & $\begin{array}{c}\text { Hueso } \\
\text { (L. guanicoe) }\end{array}$ & $380 \pm 43$ & $315-491$ & -19.5 & $2 a$ \\
\hline AA92656 & FCS. ZA1.C1.1 & $\begin{array}{c}\text { Hueso } \\
\text { (L. guanicoe) }\end{array}$ & $726 \pm 57$ & $553-721$ & -21.9 & $2 b$ \\
\hline AA94088 & FCS.ZA1.C6 & $\begin{array}{c}\text { Hueso } \\
\text { (L. guanicoe) }\end{array}$ & $793 \pm 39$ & $573 \square 739$ & -19.4 & U4 \\
\hline AA94085 & FCS.ZA1.C6 & Carbón & $1526 \pm 34$ & $1030 \square 1428$ & -22.8 & U6 \\
\hline AA94086 & FCS.ZA1.C6 & Carbón & $1527 \pm 34$ & $1302 \square 1430$ & -23.7 & U6 \\
\hline AA94087 & FCS.ZA1.C6 & $\begin{array}{c}\text { Hueso } \\
\text { (L. guanicoe) }\end{array}$ & $1508 \pm 44$ & $1289 \square 1465$ & -19.0 & U6 \\
\hline LP- 2526 & FCS.ZA.C6 & Carbón & $1330 \pm 50$ & $1077-1296$ & -24 & U6 \\
\hline AA94089 & FCS.ZA1.E1.C8 & $\begin{array}{c}\text { Hueso } \\
\text { (H. Sapiens) }\end{array}$ & $1350 \pm 41$ & $1095-1303$ & -17.1 & U1 (?) \\
\hline AA101877 & FCS.ZA1.E1.1 & $\begin{array}{c}\text { Hueso } \\
\text { (H. Sapiens) }\end{array}$ & $1438 \pm 50$ & $1185-1400$ & -17.8 & U1 (?) \\
\hline
\end{tabular}

Tabla 2. Cronología radiocarbónica del sitio Zoko Andi 1.

Table 2. Radiocarbon chronology of the Zoko Andi 1 site. 
están en curso, aunque observaciones preliminares sugieren que los entierros proceden de la U1.

De este modo, mientras que en los flancos de la duna, en especial la porción correspondiente a la barranca, la secuencia se observa condensada y están representadas las unidades 1 a 6 , en la parte superior del médano la secuencia se expande registrándose, hasta el momento, sólo la Unidad 1. Sin embargo, esta unidad debió depositarse a través de un periodo largo de tiempo ya que los entierros, que son intrusivos, indican una fecha mínima para el médano de, al menos, 1400 años AP. Futuros trabajos de campo permitirán abordar este problema.

Los materiales arqueológicos se distribuyen a lo largo de todo el perfil y serán descriptos en los próximos apartados. El material lítico y los restos faunísticos analizados provienen de las cuadrículas 4 y 6 , mientras que los restos óseos humanos proceden de las cuadrículas 8 a 10. Los materiales líticos y faunísticos, en principio fueron analizados de manera separada, siguiendo los componentes arqueológicos descriptos. Sin embargo, debido a que en este análisis preliminar no se observaron diferencias claras entre ambos componentes se presentarán los resultados generales obtenidos en cada línea de análisis. En este sentido, es necesario el análisis de una muestra mayor, que incluya a otras cuadrículas, a los efectos de evaluar si hay diferencias entre ambos componentes en los conjuntos líticos y arqueofaunísticos.

\section{Análisis faunísticos}

Se realizaron determinaciones y análisis cuantitativos para estimar medidas de abundancia anatómica y taxonómica. Además, se llevaron a cabo análisis tafonómicos para evaluar en qué medida distintos agentes y/o procesos pudieron afectar la integridad de los conjuntos zooarqueológicos, así como también para determinar el origen del ingreso de estas especies en los conjuntos. Para realizar estos análisis se consideraron las siguientes variables: meteorización (Andrews 1990; Behrensmeyer 1978), deterioro químico (Gutiérrez 2004), depositación química (e.g., carbonato y óxido de manganeso; Gutiérrez 2004), acción de roedores (Binford 1981), actividad de carnívoros (Binford 1981), pisoteo (Villa y Courtin 1983) y raíces (Behrensmeyer 1978; Montalvo 2002). Finalmente, para evaluar los efectos de la acción humana sobre los restos óseos se realizó el análisis de fracturas (Johnson 1985), huellas de corte (Olsen y Shipman 1988; Willis et al. 2008) y alteraciones térmicas (David 1990).

El conjunto faunístico está compuesto por un total de 26531 especímenes, de los cuales el 15,85\% $(n=4205)$ pudo ser determinado anatómica y taxonómicamente. De este porcentaje, el ca. $43 \%$ ( $n=1822)$ corresponde a restos óseos (Tabla 3), mientras que el ca. 57\% $(n=2383)$ restante lo constituye placas dérmicas de dasipódidos. La alta frecuencia de especímenes que no pudo ser determinado en ningún orden de especificidad se debe al alto grado de fragmentación que presenta el conjunto, sobre todo de las especies terrestres de tamaño mayor (\% completitud $=0,4)$. Con respecto a los taxones representados, la categoría Rodentia indet. $(23,44 \%$; NISP $=427)$ es la que posee la mayor frecuencia, seguida por el guanaco (21,40\%; NISP= 390), mientras que los restantes grupos taxonómicos están presentes en frecuencias menores (Tabla 3). El cálculo del NMI da cuenta de la presencia de 10 ejemplares de tuco-tuco, ocho de cuis chico, cuatro de guanaco, perca y peludo, tres de cuis común, dos de piche, martineta y perdiz común y un ejemplar de cada uno de los restantes grupos taxonómicos presentes (ver Tabla 3).

El análisis de los efectos tafonómicos se llevó a cabo sobre todos los restos óseos que pudieron ser determinados a nivel anatómico y/o taxonómico (a excepción de las placas) y todos los fragmentos mayores a $2 \mathrm{~cm}$ provenientes del material recuperado en zaranda. De esta manera, se analizó un total de 2636 especímenes. Las principales modificaciones observadas corresponden a depositaciones de carbonato $(41,77 \% ; n=1101)$, tinciones de manganeso $(39,11 \% ; n=1031)$ y marcas de raíces $(33,15 \% ; n=874)$. En menores frecuencias se registraron evidencias de meteorización $(7,20 \% ; n=190)$, marcas de roedores $(1,25 \% ; n=33)$, deterioro químico $(0,60 \% ; n=16)$, acción de carnívoros $(0,45 \% ; n=12)$ y pisoteo $(0,26 \% ; n=7)$.

Se detectaron evidencias de explotación en restos correspondientes a guanaco, venado de las pampas, armadillos y aves. En este sentido, se recuperaron 62 desechos de fractura helicoidal y una importante cantidad de fragmentos de diáfisis de huesos largos $(n=89)$ de guanaco (Figura 3A), así como una alta frecuencia de astillas de tamaño muy pequeño (menores a $2 \mathrm{~cm}$ ), que darían cuenta de la intensidad en el procesamiento de las carcasas. Asimismo, se observaron huellas de corte en 11 especímenes correspondientes tanto al esqueleto axial como apendicular de esta misma especie. Se recuperaron, además, dos instrumentos óseos, uno confeccionado en una diáfisis de metapodio y otro a partir de un fragmento de diáfisis indeterminada (Figura 3B). En el caso del venado de las pampas, un fragmento de hueso largo presenta fractura antrópica. Sumado a esto, se han identificado huellas de corte en una tibia de peludo y en dos especímenes de Dasipodidae indet. (una tibia y un metapodio; Figura $3 C$ ). Además, se registraron huellas en un tibio-tarso (Figura 3D) y en una escápula de Anatidae indet. Finalmente, se observó este tipo de modificaciones en un coracoides de un ave de tamaño mediano ( $c f$. Tinamidae). Conjuntamente, se han registrado alteraciones térmicas en el ca. 1,60\% $(n=433)$ de los restos que pudieron ser identificados anatómica y taxonómicamente.

\section{Análisis del conjunto lítico}

El análisis de los artefactos líticos estuvo orientado a 


\begin{tabular}{|c|c|c|c|c|c|}
\hline & & Taxón & NISP & NISP\% & NMI \\
\hline \multirow{10}{*}{\multicolumn{2}{|c|}{$\stackrel{\oiiint}{\gtrless}$}} & Ave indet. & 31 & 1,70 & NA \\
\hline & & Ave mediana indet. & 3 & 0,16 & NA \\
\hline & & Passeriforme & 1 & 0,06 & 1 \\
\hline & & Anatidae & 2 & 0,11 & 1 \\
\hline & & Tinamidae & 10 & 0,55 & NA \\
\hline & & Nothura maculosa (Perdiz común) & 6 & 0,33 & 2 \\
\hline & & Rhynchotus rufescens (Perdiz colorada) & 1 & 0,06 & 1 \\
\hline & & Eudromia elegans (Martineta) & 4 & 0,22 & 2 \\
\hline & & Fulica leucoptera (Gallareta chica) & 1 & 0,06 & 1 \\
\hline & & Rhea americana (Ñandú) & 4 & 0,22 & 1 \\
\hline \multirow{2}{*}{\multicolumn{2}{|c|}{ Anfibios }} & Anura indet. & 62 & 3,40 & NA \\
\hline & & Ceratophrys sp. (Escuerzo) & 13 & 0,71 & 1 \\
\hline \multirow{4}{*}{\multicolumn{2}{|c|}{ Reptiles }} & Reptilia indet. & 2 & 0,11 & NA \\
\hline & & Testudinidae (Tortuga) & 5 & 0,27 & 1 \\
\hline & & Ophidia & 40 & 2,20 & 1 \\
\hline & & Tupinambis sp. (Lagarto) & 7 & 0,38 & 1 \\
\hline \multirow{2}{*}{\multicolumn{2}{|c|}{ Peces }} & Peces indet. & 79 & 4,34 & NA \\
\hline & & Percichthys sp. (Perca) & 46 & 2,52 & 4 \\
\hline \multirow{24}{*}{ 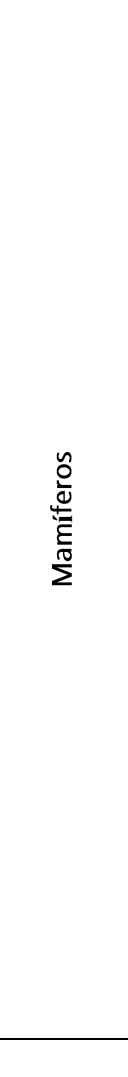 } & \multirow{7}{*}{$\begin{array}{l}\frac{\pi}{2} \\
\frac{0}{2} \\
\frac{\pi}{0} \\
.0 \\
\frac{ \pm}{2}\end{array}$} & Mesomamífero indet. & 123 & 6,75 & NA \\
\hline & & Micromamífero indet. & 40 & 2,20 & NA \\
\hline & & Artiodactyla indet. & 50 & 2,74 & NA \\
\hline & & Ovis aries / Ozotoceros bezoarticus & 2 & 0,11 & NA \\
\hline & & Ovis aries (Oveja) & 2 & 0,11 & 1 \\
\hline & & Ozotoceros bezoárticus (Venado de las pampas) & 9 & 0,49 & 1 \\
\hline & & Lama guanicoe (Guanaco) & 390 & 21,40 & 4 \\
\hline & \multirow{10}{*}{ 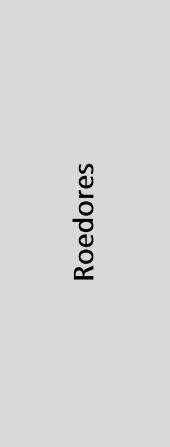 } & Rodentia indet. & 427 & 23,44 & NA \\
\hline & & Ctenomys sp. (Tuco-tuco) & 102 & 5,60 & 10 \\
\hline & & Lagostomus maximus (Vizcacha) & 5 & 0,27 & 1 \\
\hline & & Caviidae indet. & 154 & 8,45 & NA \\
\hline & & Galea leucoblephara (Cuis común) & 14 & 0,77 & 3 \\
\hline & & Microcavia australis (Cuís chico) & 30 & 1,65 & 8 \\
\hline & & Dolichotis patagonum (Mara) & 13 & 0,71 & 1 \\
\hline & & Cricetidae indet. & 23 & 1,26 & NA \\
\hline & & Akodon sp. (Ratón rojizo) & 1 & 0,06 & 1 \\
\hline & & Reithrodon auritus (Rata conejo) & 2 & 0,11 & 1 \\
\hline & \multirow{3}{*}{ Dasipódidos } & Dasypodidae indet. & 84 & 4,61 & NA \\
\hline & & Chaetophractus villosus (Peludo) & 17 & 0,93 & 4 \\
\hline & & Zaedyus pichiy (Piche) & 8 & 0,44 & 2 \\
\hline & \multirow{3}{*}{ Carnívoros } & Carnivora indet. & 6 & 0,33 & NA \\
\hline & & Conepatus chinga (Zorrino) & 2 & 0,11 & 1 \\
\hline & & Felidae indet. & 1 & 0,06 & 1 \\
\hline & & TOTAL & 1822 & 100,00 & 56 \\
\hline
\end{tabular}

Tabla 3. Taxones representados y medidas de abundancia taxonómica en el sitio Zoko Andi 1.

Table 3. Represented taxa and taxonomic abundances of the Zoko Andi 1 archaeological bone assemblage

conocer los tipos de rocas utilizados y las principales características tecnomorfológicas para las categorías artefactuales presentes. Para ello, se emplearon criterios propuestos por Aschero (1975, 1983), Bellelli et al. (1985-1987) y Armentano (2012). El análisis de cadenas operativas, incluyendo métodos y técnicas de talla, será contemplado en futuros trabajos.

El conjunto estudiado está compuesto por 3731 artefactos, distribuidos entre desechos de talla (93,97\%), ecofactos (3,32\%; se trata de rodados en todos los casos), instrumentos $(2,36 \%)$, núcleos $(0,29 \%)$ y desechos térmicos (0,05\%; Tabla 4). Teniendo en cuenta el tamaño de los ecofactos recuperados, sólo el 7,25\% de las piezas podrían considerarse posibles fuentes de materia prima, mientras que el resto $(92,75 \%)$ serían pequeños rodados propios del sedimento. En lo que concierne a la variabilidad de materias primas empleadas, las mayores 


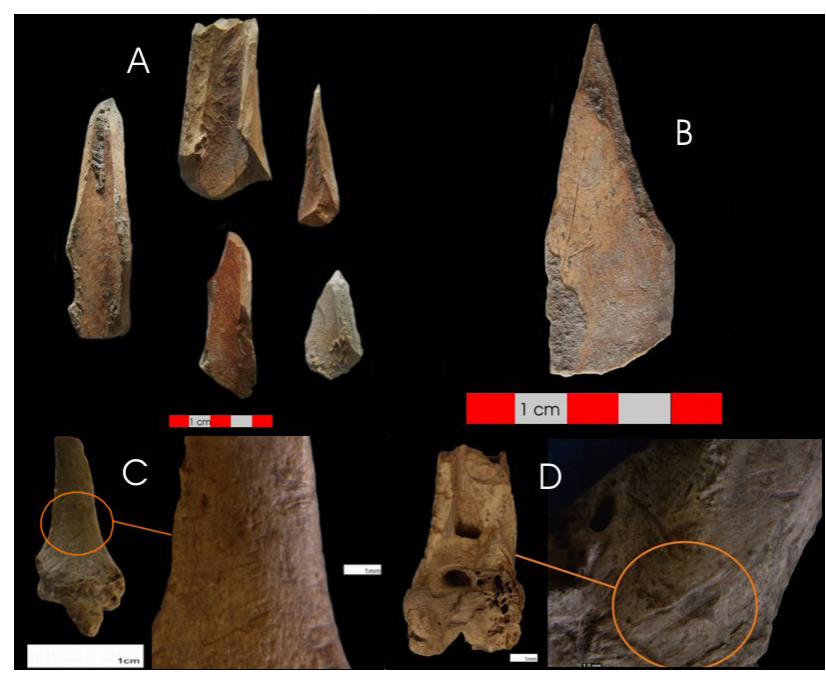

Figura 3: A) Desechos de fractura helicoidal de Lama guanicoe. B) Instrumento óseo confeccionado en un fragmento de diáfisis de Lama guanicoe. C) Tibia de Dasypodidae indet. con huellas de corte. D) Tibiotarso de Anatidae indet. con huellas de raspado.

Figure 3: A) Helical fracture debris of Lama guanicoe. B) Bone instrument made of Lama guanicoe shaft fragment. C) Cutmarks on a tibia of Dasypodidae indet. D) Cutmarks on a tibio-tarsus of Anatidae indet.

frecuencias se registran para las rocas silíceas (59,85\%) y las calcedonias (18,01\%). El resto de las rocas están representadas en proporciones menores al $10 \%$ y entre las mismas se encuentran las indeterminables (6,89\%), la calcedonia translúcida (4,34\%), el basalto/andesita $(2,39 \%)$, la tufita $(1,98 \%)$ y la dacita $(1,96 \%)$, entre otras (Tabla 4).

Con respecto a las categorías artefactuales más representadas, se registró una gran variedad de microlascas y lascas, sobresaliendo en ambos grupos las indiferenciadas $(36,38 \% ; n=1124)$, angulares recta $(12,46 \% ; n=385)$ y de arista recta $(11,26 \% ; n=348)$. Se identificó la presencia en el conjunto de lascas y microlascas de reactivación, tanto directa como inversa, que sugieren el mantenimiento de filos. En relación con las dimensiones de las lascas y microlascas, en su mayoría presentan tamaños muy pequeños $(83,07 \%$; $n=2567)$ y pequeños $(10,26 \% ; n=317)$, de espesores muy delgados $(57,96 \% ; n=1791)$ y delgados $(36,28 \% ; n=1121)$.

Los núcleos $(n=11)$ se presentan en todos los casos desarrollados sobre rodados que no sobrepasan los 5 $\mathrm{cm}$ de longitud. Si bien la mayoría de ellos $(72,75 \%)$ no pudieron adjudicarse a ningún grupo tipológico (sensu Aschero 1975, 1983), dos fueron identificados como bipolares $(18,18 \%)$ y uno como prismático parcial $(9,09 \%)$. La disposición y orientación de los lascados en cuatro de las piezas $(36,36 \%)$, así como también el número de plataformas que presentan (entre dos y cuatro), permiten inferir que los núcleos fueron rotados durante su explotación.

Dentro del conjunto de los instrumentos, pudieron diferenciarse piezas realizadas sobre soportes tallados
$(84,09 \% ; n=74)$ y no tallados $(15,91 \% ; n=14)$. En la primera categoría, se destacan los raspadores, las puntas de proyectil apedunculadas (medianas y pequeñas) y las lascas con rastros complementarios (Figura 4). También están presentes otros grupos tipológicos entre los que pueden mencionarse los instrumentos compuestos, filos en bisel asimétrico unifacial, piéces equillée, instrumentos de filos bifaciales y un fragmento de perforador.

En líneas generales, los tamaños que sobresalen son pequeño $(48,65 \%)$ y mediano pequeño $(12,16 \%)$. Los filos de los instrumentos fueron confeccionados en su gran mayoría sobre los bordes de los soportes (correspondiendo el 64,86\% a lascas de diferente tipo), por medio de retoques $(45,95 \%)$, microretoques $(14,86 \%)$ y la combinación de ambos (12,16\%). El 27,03\% restante se reparte entre piezas cuyos filos se confeccionaron por medio de la talla con retoques y microretoques. En algunos instrumentos, como las puntas de proyectil y fragmentos de estas, se observa el trabajo bifacial de los soportes, extendiéndose sobre toda la cara de la pieza. En lo que respecta al estado de los instrumentos, 18 $(24,32 \%)$ piezas presentan filos embotados, mientras que otros tres $(4,05 \%)$ poseen evidencias de haber sido reactivados.

Con respecto a los instrumentos sobre soportes no tallados, se diferencian aquellos asociados a la molienda $(54,14 \% ; n=8)$, a la talla $(28,57 \% ; n=4)$, posiblemente a la caza (fragmento de bola de boleadora) y un artefacto indiferenciado de pumicita $(7,14 \%$, en cada caso). Entre los primeros, se identificaron dos fragmentos de superficies activas, un fragmento de superficie indiferenciada y seis fragmentos de instrumentos indiferenciados, confeccionados sobre arenisca rionegrense, a excepción de un sólo caso donde se empleó un rodado de dacita. Finalmente, dentro de los instrumentos no tallados asociados a la talla, se registró la presencia de tres percutores y un fragmento de yunque.

\section{Restos humanos}

Para el análisis de los restos humanos se realizaron análisis cuantitativos (abundancia anatómica y taxonómica; Lyman 1994) y se tuvieron en cuenta criterios morfológicos para la determinación del sexo y la estimación de la edad de muerte (Buikstra y Ubelaker 1994; Scheuer y Black 2000). La excavación de tres cuadrículas $\left(3 \mathrm{~m}^{2}\right)$ en la parte superior del médano permitió hallar restos óseos humanos asociados a algunos ítems culturales como tiestos de cerámica, restos faunísticos (e.g., venado de las pampas, guanaco y peludo) y materiales de molienda (e.g., morteros y manos; Figura 5A). Durante la excavación se determinó la presencia de dos entierros bien delimitados espacialmente (Figura 5B), así como de numerosos elementos dispersos. Los hallazgos se encontraban a una profundidad de aproximadamente $70 \mathrm{~cm}$ desde la superficie del suelo y distribuidos en una potencia de $30 \mathrm{~cm}$. Por debajo de la misma, sólo se 


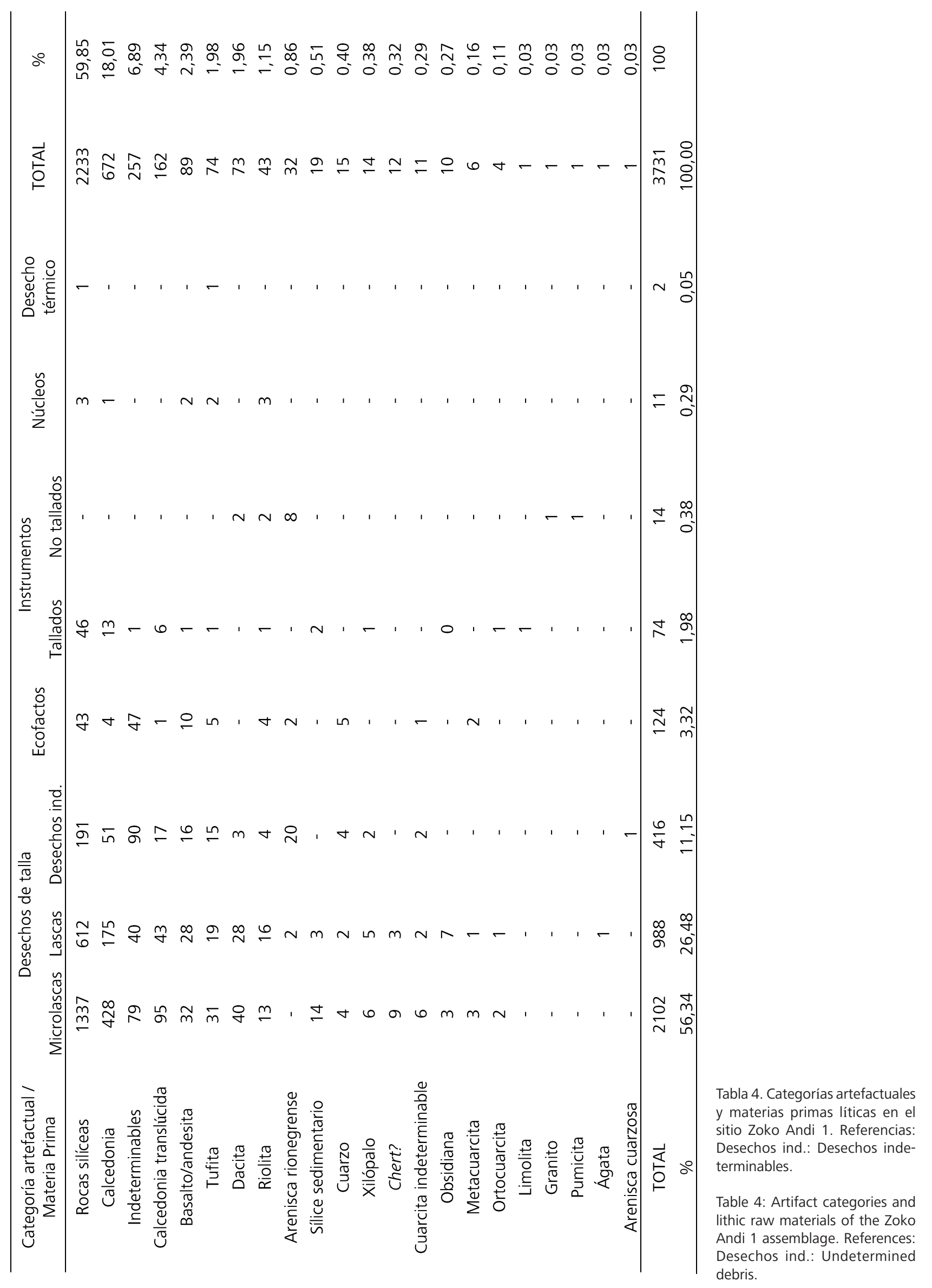



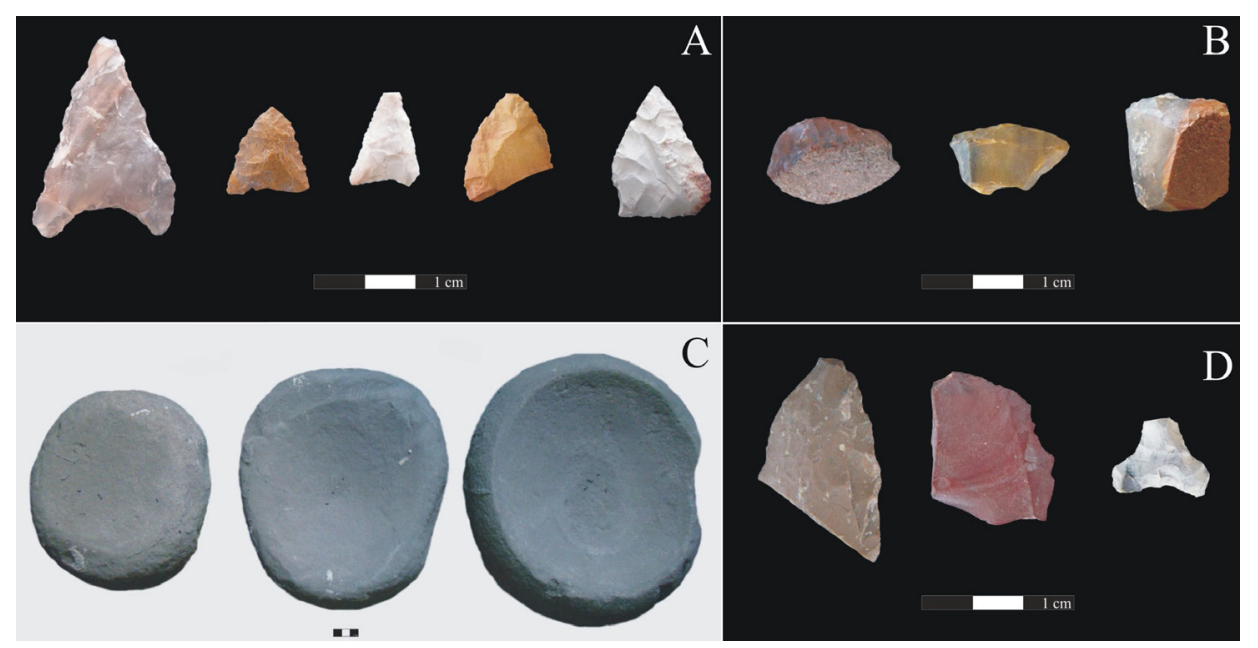

Figura 4: A) Puntas de proyectil, B) Raspadores, C) Instrumentos pasivos de molienda, D) Instrumento compuesto, pieza con machacado y un perforador fracturado.

Figure 4: A) Projectile points, B) Endscrapers, C) Grinding artifacts, D) Multipurpose tool, splintered artifact and a fracture drill. reconocieron algunos pocos elementos óseos humanos aislados. Se recuperaron 231 elementos que representan un número mínimo de 10 individuos de diversas edades y ambos sexos.

El Entierro 1 está constituido por escasas unidades anatómicas (NME $=44)$, representadas por huesos de los miembros superiores e inferiores, con ausencia del resto de los sectores esqueletales (e.g., cráneo, cinturas escapular y pélvica, tronco, columna vertebral). Se trata de un individuo masculino, adulto indeterminado. Una de las características que se destaca de este entierro es el ordenamiento espacial de los elementos de las extremidades, dado que se observó la articulación de los huesos que conforman el miembro superior derecho en posición semi-extendida dorsal y el miembro inferior izquierdo en posición decúbito dorsal flexionado. La evidencia en su conjunto sugiere una intención deliberada para seleccionar unidades de segmentación del cadáver. Los elementos óseos restantes no se localizan en una posición anatómica esperable para un esqueleto articulado. Las unidades anatómicas faltantes probablemente hayan sido recuperadas para el armado de fardos funerarios. Cabe destacar que algunos de los huesos presentan tinciones rojizas leves $y$, hasta el momento, no se han registrado huellas antrópicas. Este entierro refleja un intenso proceso de manipulación y se trata de una modalidad secundaria simple.

El Entierro 2 está conformado por 65 elementos óseos correspondientes a un individuo masculino, adulto medio. Se recuperó el cráneo y la mandíbula, la cintura escapular y pélvica, los huesos de los miembros superiores e inferiores y parte del tronco (Figura 5C). Se caracteriza por presentar el eje axial parcialmente articulado incluyendo el cráneo, algunas vértebras cervicales, dorsales y lumbares, así como costillas alineadas simétricamente. Los huesos largos de los miembros superiores e inferiores se encuentran dispuestos en forma paralela entre sí, ubicados sobre el cráneo, indicando actividades de desarticulación y reordenamiento de los mismos. Un caso llamativo lo constituyen los huesos que componen la mano izquierda completa y articulada dispuesta sobre el entierro, sugiriendo la segmentación de esta porción del esqueleto cuando el individuo aún tenía partes blandas. No obstante, no se han registrado hasta el momento huellas de desarticulación en los elementos analizados. Esto podría deberse a la acción de procesos culturales (e.g., técnicas de desarticulación) y/o naturales (e.g., depositaciones de carbonato y marcas de raíces sobre la superficies óseas) que no permitieron su identificación. De acuerdo con esta descripción, es posible plantear como hipótesis que la modalidad de entierro de este individuo es una "disposición" (sensu Berón et al. 2002:101). La mayoría de los huesos presentan en su superficie tinciones rojizas intensas. Un rasgo destacable en este entierro es la presencia de dos tembetaes confeccionados sobre tejido óseo (Figura 5D), asociados espacialmente a la mandíbula.

Además de las unidades anatómicas que componen los Entierros 1 y 2, se recuperaron 122 elementos dispersos en la planta de excavación, sin correspondencia anatómica y que no pudieron ser asignados a ninguno de los entierros. Se recuperaron elementos pertenecientes a un individuo perinato, un infante, un juvenil y cinco adultos.

\section{Discusión}

Dada la información provista en los apartados anteriores se brindan aquí las principales tendencias surgidas del análisis preliminar de las cuadrículas excavadas en el sitio. Los estudios geoarqueológicos y la cronología obtenida indican claramente dos componentes (inferior y superior) en una misma secuencia estratigráfica, localizada en las barrancas adyacentes al río (Figura 2). El componente inferior se ubica entre ca. 1500-1300 años AP y está relacionado con dinámicas de ambientes fluviales. El componente superior, vinculado a procesos eólicos y pedogenéticos, se localiza cronológicamente entre $c a$. 800-400 años AP. Pero, además de esta secuencia, en la parte superior del médano (cuadrículas 8, 9 y 10) se recuperaron los entierros datados en ca. 1400 años AP. Es decir, el sitio presenta algunos sectores exclusivamente relacionados a la depositación y/o descarte de elementos 


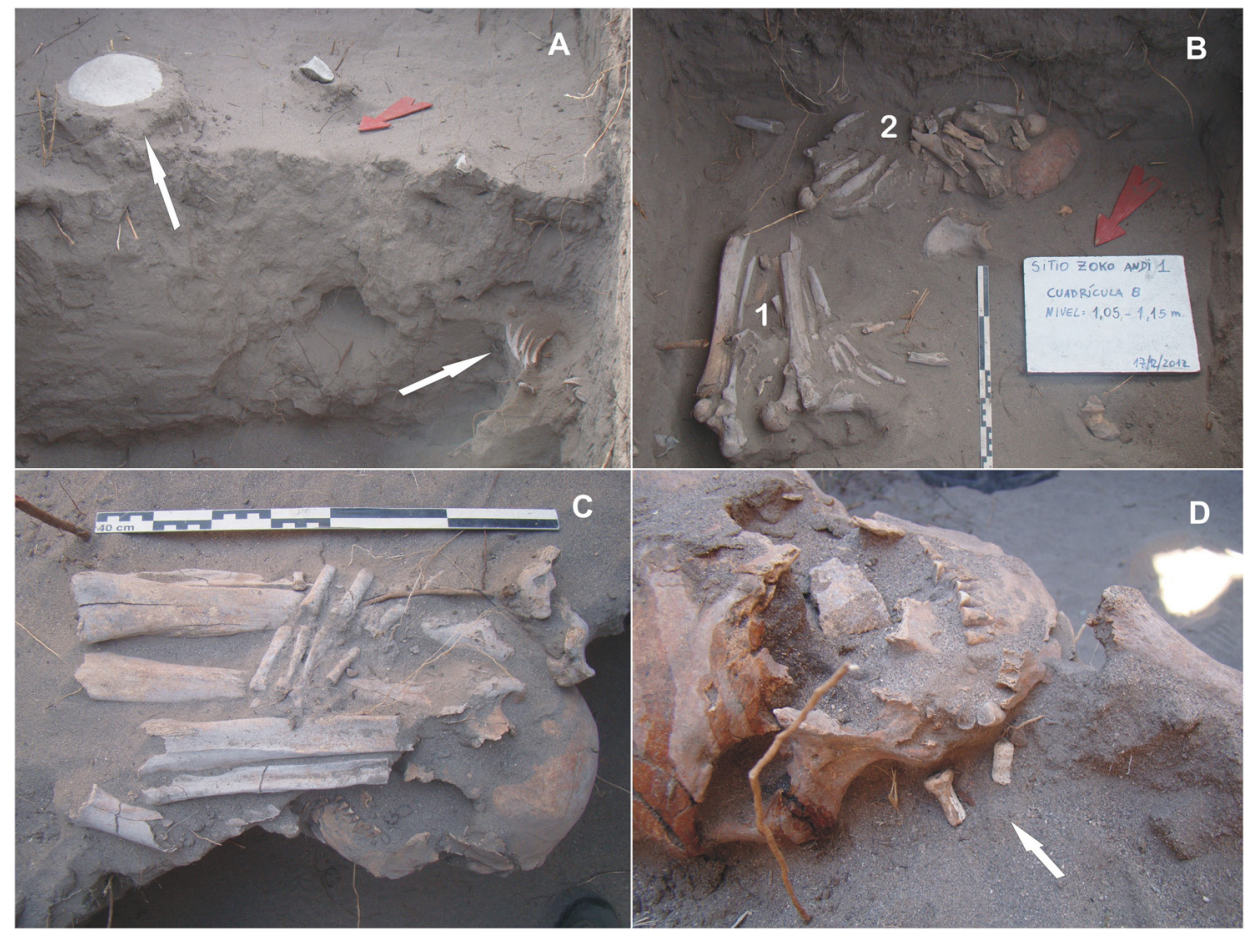

Figura 5: A) Relación espacial estratigráfica entre los materiales de molienda y los entierros humanos. B) Localización de los Entierros 1 y 2. C) Características y ubicación de las unidades anatómicas del Entierro 2. D) Presencia de dos tembetaes asociados espacialmente a la mandíbula del individuo del Entierro 2.

Figure 5: A) Stratigraphic spatial relation between grinding materials and human burials. B) Location of burials 1 and 2. C) Characteristics and location of the anatomical units of Burial 2. D) Presence of two "tembetaes" (lip ornaments) spatially associated with the mandible of Burial 2.

vinculados a lo doméstico (e.g., cerámica, desechos de fractura helicoidal, artefactos líticos, etc.), mientras que, en forma coetánea, otros sectores del sitio fueron usados para inhumaciones y para tareas domésticas. De este modo, para el lapso 1500-1300 años AP, el registro arqueológico indica un patrón claramente relacionado a variabilidad intrasitio. En ambientes áridos-semiáridos, como los que caracterizan al área, y dadas las intensas condiciones de morfogénesis destacadas para algunos sitios de la misma (Martínez y Martínez 2011), el patrón registrado en Zoko Andi 1 ofrece una situación poco común en este tipo de ambientes, en relación con la integridad y resolución del registro arqueológico. Por primera vez también para el área se registró carbón vegetal, del cual se obtuvieron varios de los fechados radiocarbónicos (Tabla 2). Análisis antracológicos en curso indican que se trata de Prosopis caldenia (Brea 2012).

Los análisis faunísticos mostraron la presencia de una importante diversidad de taxones representados ( $\mathrm{N}=$ 26) a lo largo de la secuencia (Tabla 2). Con respecto a las especies explotadas, se registraron evidencias de consumo en taxones de tamaño mayor (guanaco y venado) y menor (armadillos y aves), provenientes de ambientes tanto terrestres como fluviales. En el caso de las primeras, se estima un probable aprovechamiento intensivo de ungulados reflejado en el alto grado de fragmentación que presenta el conjunto, la elevada frecuencia de desechos de fractura antrópica, la presencia de lascas óseas, etc. (Figura 3). Esta evidencia, si bien se observa a lo largo de toda la secuencia estratigráfica, se concentra principalmente entre los niveles que corresponden a la U6 y aquellos que comprenden la parte inferior de la U4. Esto, en principio, sugiere que el consumo intensivo de ungulados habría ocurrido desde momentos más tempranos (ca. 1500-1300 años AP) respecto de lo que se había propuesto como parte del modelo de subsistencia planteado para el área (Stoessel 2012, 2014a). En el caso del venado de las pampas, si bien presenta evidencias de consumo, la frecuencia de restos óseos es muy baja como para profundizar en aspectos vinculados con su explotación. Con respecto a las especies de tamaño menor, los especímenes con evidencias de consumo se recuperaron en los niveles que corresponden al componente superior (ca. 800-400 años AP). Esto es concordante con la evidencia obtenida hasta el momento en el área de estudio (e.g., sitio El Tigre) que muestra el consumo de especies pequeñas preferentemente durante el Holoceno tardío final (Alcaráz 2013). Los resultados alcanzados son, sin embargo preliminares. Será necesaria la ampliación de la muestra a través de la excavación y análisis de nuevas cuadrículas para profundizar las tendencias obtenidas y evaluar si existieron diferencias en la explotación de recursos faunísticos a través del tiempo.

Por otra parte, la información obtenida de los análisis tafonómicos es consistente con la dinámica de depositación inferida desde los estudios geoarqueológicos. En este sentido, en los restos faunísticos provenientes de las unidades que corresponden al componente inferior (U5 y U6) se observa una elevada frecuencia de especímenes con tinciones de manganeso (ca. 25\%) y depositaciones de carbonato (ca. 58\%), a diferencia del componente superior (manganeso=ca. 16\%; carbonato=ca. 28\%). Esto podría estar vinculado a la desactivación del meandro y al contexto fluvial que caracteriza a estos depósitos. En el caso de las unidades que corresponden al componente superior (U1 a U4), las principales modificaciones observadas en las superficies óseas fueron consecuencia de la acción de las raíces (ca. 42\%), mientras que en el componente inferior ésta se registra en menor frecuencia (ca. 17\%). Esta situación sería el resultado de eventos 
pedogenéticos en la parte superior de la secuencia.

En lo que respecta a la tecnología lítica, las materias primas empleadas y las categorías artefactuales representadas muestran tendencias similares a las de otros sitios del área (e.g., El Tigre y localidad arqueológica San Antonio; Armentano 2012) ubicados temporalmente en el Holoceno tardío final (ca. 1000-400 años AP). Los resultados indican el predominio de rocas de procedencia local y areal, como sílices y calcedonias. Las materias primas extra-areales están representadas por el granito, la ortocuarcita, la metacuarcita, la limolita silicificada, la calcedonia translúcida, un posible chert silíceo y una calcedonia -hasta el momento indeterminable- sobre la cual se confeccionó una punta de proyectil (Figura 4). Estas materias primas extra-areales provendrían de regiones ubicadas al sur (e.g., posiblemente Golfo San Matías y Meseta de Somuncurá para las calcedonias), al norte (e.g., cordones serranos bonaerenses, en los casos de las cuarcitas, el granito y la limolita) y, posiblemente, al oeste (Meseta del Fresco para el posible chert silíceo) del área de estudio, como ha sido destacado en otros trabajos (Armentano 2012; Santos Valero 2013). El futuro análisis de los procesos de talla permitirá discriminar si existió una gestión diferencial de estas materias primas entre el Holoceno tardío inicial y final en el sitio. Con respecto a los instrumentos tallados, los raspadores y las puntas de proyectil son los grupos tipológicos más representados, confeccionados casi en su totalidad sobre rocas silíceas y calcedonias, aspecto que también se observa en los sitios del Holoceno tardío final anteriormente mencionados. Tanto en el sitio El Tigre como en la localidad arqueológica San Antonio predominan las puntas triangulares apedunculadas (Armentano 2012), similares a las registradas en Zoko Andi 1. Los instrumentos no tallados asociados a la molienda recuperados en superficie y estratigrafía presentan características formales (Figura 4) y fueron confeccionados exclusivamente en areniscas rionegrenses. Si bien no se ha llevado a cabo aún el análisis de las cadenas operativas, los resultados obtenidos hasta el momento permiten plantear la producción in situ de la mayoría de los instrumentos, sobre todo de aquellos confeccionados sobre rodados areales y locales. Sin embargo, la presencia de instrumentos terminados sobre rocas extra-areales (cuarcitas, calcedonia translúcida, calcedonia indeterminable y limolita), sugiere el ingreso al sitio de artefactos con cierto grado de formatización o de instrumentos terminados. La presencia de microlascas de reactivación y de instrumentos con evidencias de reavivado dan cuenta del mantenimiento de estos artefactos en el sitio, así como el abandono de piezas ya agotadas (filos reactivados y muy embotados).

En el curso inferior del río Colorado, el registro bioarqueológico presentó variaciones en las prácticas mortuorias a través del Holoceno tardío. En este sentido, para momentos previos a los ca. 800 años AP, las modalidades de entierros se caracterizaron por la modalidad primaria simple en áreas residenciales (e.g.,
La Primavera y El Puma 2), mientras que para momentos posteriores se registra, además, la modalidad secundaria múltiple y las áreas formales de entierro (e.g., La Petrona y Paso Alsina 1; ver Martínez et al. 2012a). De acuerdo con esto, el sitio Zoko Andi 1 presenta el registro más temprano (ca. 1400 años AP) para la transición pampeanopatagónica oriental, en lo que respecta a la manipulación de partes esqueletarias. Además, se registraron nuevas modalidades de entierro, "disposiciones", asociadas a contextos de inhumación secundarios. Respecto de la cronología obtenida para ambos entierros se observa una sincronía en el ritual funerario. Como se comentó más arriba, esta cronología coincide con las ocupaciones detectadas en el componente inferior (U6; Figura 2 y Tabla 1).

Un hallazgo novedoso en este sitio es la presencia de dos tembetaes registrados en estrecha asociación espacial con la mandíbula del Entierro 2. Este contexto de hallazgo indica que estos artefactos ocuparon su posición original cuando el individuo inhumado aun poseía partes blandas. El fechado obtenido del mismo, entonces, sugiere el uso de estos adornos labiales hacia el ca. 1400 años AP. Hasta el momento sólo se contaba con la presencia de adornos labiales y posiblemente auriculares hallados en superficie en el sitio La Petrona (Martínez y Figuerero Torres 2000), asignado a un contexto del Holoceno tardío final (800250 años AP; Flensborg et al. 2011).

\section{Conclusión}

El sitio Zoko Andi 1 constituye un contexto excepcional para el curso inferior del río Colorado. Por primera vez se pudo discriminar en una misma secuencia dos componentes, en función de las variables cronológicas y de dinámicas ambientales. Si bien por el momento esto no pudo ser establecido para las demás líneas de análisis, se deberá, a futuro, realizar un análisis exhaustivo de una muestra artefactual mayor y su distribución a través de la estratigrafía.

Claramente se trata de un asentamiento intensamente reocupado a través del tiempo para distintos propósitos, detectándose una importante variabilidad intrasitio para el lapso de ca. 1500-400 años AP. Los datos obtenidos del estudio de los conjuntos faunísticos y líticos se ajustan parcialmente a aquellos propuestos en los modelos tecnológicos de aprovisionamiento de materias primas y de subsistencia planteados para el área (Armentano 2012; Alcaráz 2012; Santos Valero 2013; Stoessel 2012), y es fundamental analizar una muestra más representativa para evaluar estos resultados preliminares. Las tendencias de estas líneas de evidencia para el sitio indican contextos residenciales, de actividades múltiples. Se recuperaron a través de toda la secuencia estratigráfica 171 tiestos cerámicos que aún no han sido analizados. La presencia de cerámica está en sintonía con esta asignación funcional y su presencia en el componente inferior (1500-1300 años AP) indica una cronología relacionada al Holoceno tardío 
inicial, como ha sido observado en el sitio Loma Ruiz 1 (1900-1600 años AP; Martínez et al. 2011). El contexto mortuorio cuenta con un número elevado de individuos de ambos sexos y diferentes edades de muerte. Se observa una sectorización del sitio (e.g., la cima del médano; cuadriculas 8, 9 y 10) acorde a funciones específicas (e.g., inhumaciones). Sin embargo, la presencia de algunos ítems faunísticos, líticos, cerámicos y materiales de molienda localizados inmediatamente por encima de los entierros (Figura 5D) indicaría el uso simultáneo de ciertos sectores del sitio para fines domésticos/sagrados, tal como ha sido propuesto para la mayoría de los sitios con entierros humanos en el área de estudio (Martínez 2010) y de regiones vecinas (ver Martínez et al. 2012a; Prates y Di Prado 2013 y referencias allí citadas). Desde una perspectiva regional, Zoko Andi 1 representa el antecedente más temprano de manipulación antrópica de cadáveres para el noreste de Patagonia y la subregión Pampa Seca, cuya cronología no superaba los 1200 años AP (Berón et al. 2007; Gómez Otero y Dahinten 1997-1998; Mariano 2011; Mendonça et al. 2010). No obstante, esta situación difiere de lo registrado para el sudeste de la región Pampeana donde los procesos de manipulación de cadáveres son más tempranos (Mazzia et al. 2004; Scabuzzo y Politis 2010).

Como se observó a lo largo de todo el trabajo, el sitio Zoko Andi 1 constituye un importante antecedente arqueológico para el área de estudio que permite complementar las diferentes líneas de análisis hasta el momento desarrolladas en la transición pampeanopatagónica oriental. En este sentido, los estudios realizados aportaron información novedosa para discutir algunos aspectos de los modelos de subsistencia, de la organización de la tecnología lítica, de las prácticas mortuorias y de la organización social propuestos para los grupos cazadores-recolectores que ocuparon el área durante el Holoceno tardío. Además, sitios recientemente detectados (Cantera de Rodados Villalonga, Loma de Los Morteros y La Modesta) han sido datados en el lapso ca. 5.600 y 4.200 años AP, en el Holoceno medio (Carden y Martínez 2014; Martínez et al. 2012b; Stoessel 2014b). Estos hallazgos novedosos para el curso inferior del río Colorado, permitirán profundizar y reevaluar el modelo al que se hizo referencia al comienzo de este trabajo, que solo contempla al Holoceno tardío, y sus implicaciones para otros modelos regionales desarrollados para Pampa y Norpatagonia.

Olavarría, 30 de junio de 2014

\section{Agradecimientos}

Los trabajos de campo y los análisis efectuados en el sitio fueron posibles gracias a subsidios otorgados por el CONICET (PIP-CONICET N 338) y ANPCYT (PICT N²64). Agradecemos a la UE INCUAPA-CONICET por el soporte institucional. Agradecemos al Dr. Pablo Messineo y a dos revisores anónimos quienes realizaron importantes comentarios. Guillermo Luro, Augusto Crocioni, Oscar y René Scwalie nos ofrecieron generosamente su apoyo e instalaciones en el establecimiento Zoko Andi. Esto facilitó enormemente nuestros trabajos de campo y les estamos muy agradecidos. Lo expuesto aquí es, desde luego, responsabilidad de los autores.

\section{Bibliografía}

Alcaráz, A. P. 2012. "Análisis zooarqueológico y tafonómico de restos óseos de pequeños vertebrados de sitios del curso inferior del río Colorado (pcia. de Buenos Aires) durante el Holoceno tardío. Aportes para el conocimiento de la subsistencia y procesos de formación". Facultad de Ciencias Sociales, Universidad Nacional del Centro de la Provincia de Buenos Aires, Argentina. 206 páginas. Tesis de grado. FACSO-UNICEN, Olavarría.

Alcaráz, A. P. 2013. Aprovechamiento antrópico de fauna menor en el curso inferior del río Colorado (transición pampeano-patagónica oriental): el sitio El Tigre como caso de estudio. Intersecciones en Antropología, en prensa.

Andrews, P. 1990. Ow/s, Caves and Fossils. The University of Chicago Press, Londres.

Armentano, G. 2012. "Arqueología del curso inferior del Río Colorado. Estudio tecnológico de las colecciones líticas de Norpatagonia Oriental durante el Holoceno tardío. Departamentos de Villarino y Patagones, Provincia de Buenos Aires. Argentina". Universidad Nacional del Centro de la Provincia de Buenos Aires, Argentina y Université de Paris Ouest Nanterre- La Défense, Francia. 543 páginas. Tesis de postgrado en cotutela. Olavarría y Nanterre. FACSOUNICEN, Olavarría.

Aschero, C. 1975. Ensayo para una clasificación morfológica de artefactos líticos aplicada a estudios tipológicos comparativos. Ms. Informe presentado al CONICET

Aschero, C. 1983. Guías de clase de clasificación de artefactos líticos. Ms. Cátedra de Ergología y Tecnología. Facultad de Filosofía y Letras, UBA.

Barrientos, G. y S. I. Perez. 2004. La expansión y dispersión de poblaciones del norte de Patagonia durante el Holoceno tardío: evidencia arqueológica y modelo explicativo. Civalero, M. T., P. M. Fernández, A. G. Guraieb (Eds.), Contra viento y marea. Arqueología de la Patagonia, pp. 179-195. Instituto de Antropología y Pensamiento Latinoamericano, Buenos Aires.

Behrensmeyer, A. 1978. Taphonomic and Ecology Information from Bone Weathering. Paleobiology 4: 150162.

Bellelli, C., G. Guráieb y J. García. 1985-87. Propuesta para el análisis y procezamiento por computadora de desechos de talla lítica (DELCO- Desechos Líticos Computarizados). 
Arqueología Contemporánea II (1): 36-53.

Berón, M. A. 2004. “Dinámica poblacional y estrategias de subsistencia de poblaciones prehispánicas de la cuenca Atuel-Salado-Chadileuvú-Curacó, Provincia de La Pampa". Facultad de Filosofía y Letras, Universidad de Buenos Aires, 454 páginas. Tesis de postgrado.

Berón, M., I. Baffi, R. Molinari, C. Aranda, L. Luna y A. Cimino. 2002. El Chenque de Lihue Calel. Una estructura funeraria en las "Sierras de la vida". Mazzanti, D.L., M. Berón, F.W. Oliva (Eds.), Del Mar a los Salitrales. 10.000 de Historia Pampeana en el Umbral del Tercer Milenio, pp. 87106. Laboratorio de Arqueología, Facultad de Humanidades, UNMdP, Mar del Plata.

Berón, M., C. Aranda y L.H. Luna. 2007. Variabilidad y tendencias temporales de las prácticas mortuorias en el Sitio Chenque I. En: Tras las huellas de la materialidad. Resúmenes ampliados del XVI Congreso Nacional de Arqueología Argentina, pp. 247-253. Facultad de Humanidades y Ciencias Sociales. Universidad Nacional de Jujuy. San Salvador de Jujuy.

Binford, L. 1981. Bones: Ancient Men and Modern Myths. Academic Press, New York.

Brea, M. 2012. Análisis de carbones arqueológicos del Sitio Zoko Andi, Rio Colorado, provincia de Buenos Aires, Argentina. Ms. Informes del Laboratorio de Paleobotánica (CICYTTP-Diamante) 24.

Buikstra, J. y D. Ubelaker. 1994. Standars for data collection from human skeletal remains. Arkansas Archaeological Survey Research Series N 44, Arkansas.

Carden, N. y G. Martínez. 2014. Diseños fragmentados. Circulación social de imágenes sobre huevos de Rheidae en Pampa y Norpatagonia. Trabajo aceptado para su publicación en el Boletín del Museo Chileno de Arte Precolombino 19.

David, B. 1990. How was this bone burnt?. Solomon, S., I. Davidson y D. Watson (Eds.), Problem Solving in Taphonomy: Archaeological and Paleontological Studies from Europe, Africa and Oceania, Volumen 2, pp. 65-79, University of Queensland, Queensland.

Favier Dubois, C. M., F. Borella y R. H. Tykot. 2009. Explorando tendencias en el uso humano del espacio y los recursos en el litoral rionegrino (Argentina) durante el Holoceno medio y tardío. Salemme, M., F. Santiago, M. Álvarez, E. Piana, M. Vázquez y M. E. Mansur (Comp.), Arqueología de la Patagonia: una mirada desde el último confín, compilado, pp. 985-997. Editorial Utopias, Ushuaia, Tierra del Fuego.

Flensborg, G. 2012. "Análisis paleopatológico en el curso inferior del río Colorado (Pcia. de Buenos Aires). Exploración y evaluación del estado de salud de sociedades cazadorasrecolectoras en el Holoceno tardío". Facultad de Ciencias Sociales, Universidad Nacional del Centro de la Provincia de Buenos Aires, Olavarría, Argentina. 420 páginas. Tesis de postgrado. FACSO-UNICEN, Olavarría.

Flensborg, G., G. Martínez, M. González y P. Bayala. 2011. Revisión de los restos óseos humanos del sitio La Petrona (transición pampeano-patagónica oriental, Argentina). Magallania 39 (1): 5-14.

Gómez Otero, J. 2006. "Recursos, dieta y movilidad en la costa centro-septentrional de Patagonia durante el Holoceno tardío". Facultad de Filosofía y Letras, Universidad de Buenos Aires, Buenos Aires. 465 páginas. Tesis de postgrado.

Gómez Otero, J. y S. Dahinten. 1997-1998. Costumbres funerarias y esqueletos humanos: variabilidad y poblamiento en la costa nordeste de la provincia de Chubut (Patagonia, Argentina). Relaciones de la Sociedad Argentina de Antropología XXII-XXIII: 101-124.

Gordón, F. 2011. "Dinámica poblacional, Conflicto y Violencia en el Norte de Patagonia durante el Holoceno tardío: un Estudio Arqueológico". Facultad de Ciencias Naturales y Museo, Universidad Nacional de La Plata. 346 páginas. Tesis de postgrado.

Gutiérrez, M. 2004. "Análisis tafonómicos en el área Interserrana (Provincia de Buenos Aires)". Facultad de Ciencias Naturales y Museo, Universidad Nacional de La Plata, Argentina. 498 páginas. Tesis de postgrado. FCNyM, UNLP, La Plata.

Johnson, E. 1985. Current Developments in Bone Technology. Schiffer, M.B. (Ed.), Advances in Archeological Method and Theory, pp. 157-235, Academic Press, New York.

Lyman, R. 1994. Vertebrate Taphonomy. Cambridge Manuals in Archaeology. Cambridge University Press, Cambridge.

Mariano, C.I. 2011. Prácticas mortuorias y registro bioarqueológico en la costa rionegrina del golfo San Matías, Argentina. Intersecciones en Antropología 12: 17-30.

Martínez, G. 2008-2009. Arqueología del curso inferior del río Colorado: estado actual del conocimiento e implicaciones para la dinámica poblacional de cazadores recolectores pampeano-patagónicos. Cazadores-Recolectores del Cono Sur. Revista de Arqueología 3: 71-92.

Martínez, G. 2010. Entierros humanos en lugares sagrados y domésticos durante el Holoceno tardío: el registro bioarqueológico del curso inferior del río Colorado (provincia de Buenos Aires, Argentina). Revista Werkén 13: 145-160.

Martínez, G. y M. J. Figuerero Torres. 2000. Sitio arqueológico La Petrona (Pdo. de Villarino, Pcia. de Bs. As.): Análisis de 
las modalidades de entierro en el área Sur pampeana. Relaciones de la Sociedad Argentina de Antropología XXV: 227-247.

Martínez, G. y G.A. Martínez. 2011. Late Holocene environmental dynamics in fluvial and Aeolian depositional settings: archaeological record variability at the lower basin of the Colorado River (Argentina). Quaternary International 245 (1): 89-102.

Martínez, G., P. Madrid y A. Bonetti. 2011. Análisis tecnomorfológico de la alfarería del sitio Loma Ruíz 1 (curso inferior del río Colorado, provincia de Buenos Aires). VI Congreso de Arqueología de la Región Pampeana Argentina. Revista del Museo de La Plata 12 (86): 47-48.

Martínez, G., G. Flensborg y P. Bayala. 2012a. Human corpse manipulation and the body as symbol: A case study from the Eastern Pampa-Patagonian transition (Argentina) during the Final Late Holocene. Journal of Anthropological Archaeology 31: 215-226.

Martínez, G., G. Flensborg y P. Bayala. 2012b. Primeras evidencias de restos óseos humanos en el curso inferior del río Colorado durante el Holoceno medio: sitio Cantera de Rodados Villalonga (Pdo. de Patagones, Pcia. de Buenos Aires). Cazadores Recolectores del Cono Sur. Revista de Arqueología 6: 95-106.

Mazzanti, D. 2006. La constitución de territorios sociales durante el Holoceno tardío. El caso de las sierras de Tandilia. Argentina. Relaciones de la Sociedad Argentina de Antropología XXXI: 277-300.

Mazzia, N.I., C. Scabuzzo y R. Guichón. 2004. Sobre cráneos, pelvis y otros huesos. Entierros humanos en el sitio El Guanaco. Martínez, G., M. Gutiérrez, R. Curtoni, M. Berón y P. Madrid (Eds.), Aproximaciones Arqueológicas Pampeanas: Teorías. Métodos y Casos de Aplicación Contemporáneos, pp. 293-304. Facultad de Ciencias Sociales. Universidad Nacional del Centro de la Provincia de Buenos Aires, Olavarría.

Mendonça, O.J., A.M. Aguerre, M.A. Bordach, M. Ammann, A.M. Arrieta, M.C. Croatto y L.M. Pera. 2010. Inclusiones funerarias y dimensiones sociales del comportamiento mortuorio en el Médano Petroquímica, Departamento Puelen, Provincia de La Pampa. Berón, M., L. Luna, M. Bonomo, C. Montalvo, C. Aranda y M. Carrera Aizpitarte (Eds.), Mamul Mapü: pasado y presente desde la arqueología pampeana, pp. 227-237. Libros del Espinillo, Ayacucho, Buenos Aires.

Montalvo, C.I. 2002. Root traces in fosil bones from the Huayquerian (Late Miocene) faunal assemblage of Telén, La Pampa, Argentina. Acta Geológica Hispánica 37(1): 37-42.

Olsen, S. y P. Shipman. 1988. Surface Modification on Bone: Trampling versus Butchering. Journal of Archaeological
Science 15: 535-553.

Politis, G. 2008. The pampas and campos of South America. Silverman, H. y W. Isbell (Eds.), Handbook of South American Archaeology, Cap. 14, pp. 235-260. Springer, New York.

Prates, L. 2008. Los indígenas del río Negro. Un enfoque arqueológico. Colección de Tesis Doctorales, Sociedad Argentina de Antropología. Buenos Aires.

Prates, L. y V. Di Prado. 2013. Sitios con entierros humanos y ocupaciones residenciales en la cuenca del río Negro (norpatagonia, Argentina). Diacronía y multicausalidad. Latin American Antiquity 24(3), en prensa.

Santos Valero, F. 2013. "Tendencias tencológicas de los sitios El Puma 3 y 4 (Partido de Villarino, Provincia de Buenos Aires). Contribución al conocimiento de la explotación de recursos líticos durante el Holoceno tardío inicial". Facultad de Ciencias Sociales, Universidad Nacional del Centro de la Provincia de Buenos Aires. 249 páginas. Tesis de grado. FACSO-UNICEN, Olavarría.

Scabuzzo, C. y G. Politis. 2010. Los entierros secundarios del Holoceno temprano y medio en la región pampeana. Nuevos datos del sitio Arroyo Seco 2. Cazadores Recolectores del Cono Sur 4: 135-155.

Scheuer, L. y S. Black. 2000. Developmental juvenile osteology. Academic Press. Londres.

Stoessel, L. 2012. "Análisis zooarqueológicos en el curso inferior del río Colorado (provincia de Buenos Aires). Aportes para el conocimiento de la subsistencia de cazadoresrecolectores en el Holoceno tardío". Facultad de Ciencias Sociales, Universidad Nacional del Centro de la Provincia de Buenos Aires, Olavarría, Argentina. 380 páginas. Tesis de postgrado. FACSO-UNICEN, Olavarría.

Stoessel, L. 2014a. Evaluating intensity in the processing of guanaco (Lama guanicoe) at the lower basin of the Colorado river (Argentina): fragmentation levels and fracture patterns analysis. International Journal of Osteoarchaeology 24: 51-67.

Stoessel, L. 2014b. Tendencias preliminares en el consumo de peces durante el Holoceno tardío en el área de transición pampeano-patagónica oriental (pcia. de Buenos Aires). Trabajo aceptado para su publicación en la Revista Archaeofauna. International Journal of Archaeozoology 24.

Villa, P. y J. Courtin. 1983. The Interpretation of Stratified Sites: A View from Underground. Journal of Archaeological Science 10: 267-281.

Willis, L.M., M.I. Eren y T.C. Rick. 2008. Does butchering fish leave cut marks? Journal of Archaeological Science 35: 1438-1444. 